\title{
The effects of amlodipine and platelet rich plasma on bone healing in rats
}

\author{
This article was published in the following Dove Press journal: \\ Drug Design, Development and Therapy \\ 7 April 2015 \\ Number of times this article has been viewed
}

\author{
Yusuf Atalay' \\ Mehmet Fatih Bozkurt ${ }^{2}$ \\ Yucel Gonul ${ }^{3}$ \\ Omer Cakmak ${ }^{4}$ \\ Kamil Serkan Agacayak ${ }^{5}$ \\ Ibrahim Köse ${ }^{6}$ \\ Omer Hazman ${ }^{7}$ \\ Hikmet Keles ${ }^{2}$ \\ Ozan Turamanlar ${ }^{3}$ \\ Mehmet Eroglu ${ }^{8}$ \\ 'Department of Oral and Maxillofacial \\ Surgery, Faculty of Dentistry, Afyon \\ Kocatepe University, Afyonkarahisar, \\ Turkey; ${ }^{2}$ Department of Pathology, \\ Faculty of Veterinary Medicine, Afyon \\ Kocatepe University, Afyonkarahisar, \\ Turkey; ${ }^{3}$ Department of Anatomy, \\ Faculty of Medicine, Afyon Kocatepe \\ University, Afyonkarahisar, Turkey; \\ ${ }^{4}$ Department of Periodontology, \\ Faculty of Dentistry, Afyon Kocatepe \\ University, Afyonkarahisar, Turkey; \\ ${ }^{5}$ Department of Oral and Maxillofacial \\ Surgery, Faculty of Dentistry, Dicle \\ University, Diyarbakır, Turkey; \\ ${ }^{6}$ Department of Oral and Maxillofacial \\ Surgery, Faculty of Dentistry, \\ Adıyaman University, Adıyaman, \\ Turkey; ${ }^{7}$ Department of Biochemistry, \\ Faculty of Sciences, Afyon Kocatepe \\ University, Afyonkarahisar, Turkey; \\ ${ }^{8}$ Department of Orthopedics and \\ Traumatology, Faculty of Medicine, \\ Afyon Kocatepe University, \\ Afyonkarahisar, Turkey
}

Correspondence: Yusuf Atalay Department of Oral and Maxillofacial Surgery, Faculty of Dentistry, Afyon Kocatepe University, 03030 Afyonkarahisar, Turkey Tel +90272 216 7900-1038-1025

Email dratalay@aku.edu.tr
Aim: The aim of this study was to evaluate the effects of calcium channel blocker (CCB) amlodipine (AML), platelet rich plasma (PRP), and a mixture of both materials on bone healing.

Materials and methods: Fifty-six male Wistar rats were randomly divided into four groups: group A, tibia defect model with no treatment; group B, tibia defect model treated with AML, $0.04 \mathrm{mg}$ daily by oral gavage; group C, tibia defect model treated with local PRP; group D, tibia defect model treated with local PRP and AML, $0.04 \mathrm{mg}$ daily by oral gavage.

Results: At day 21, bone healing was significantly better in groups $\mathrm{C}$ and $\mathrm{D}$ compared to group A $(P<0.05)$, but comparisons showed no statistically significant difference in group B $(P>0.05)$. At day 30 , groups $\mathrm{B}$ and $\mathrm{C}$ showed no statistically significant difference $(P>0.05)$ compared to group $\mathrm{A}$, but bone healing in group $\mathrm{D}$ was significantly better than in group $\mathrm{A}$ $(P<0.05)$. Statistically, AML did not affect alkaline phosphatase (ALP) activity at 21 and 30 days $(P>0.05)$, but PRP and AML + PRP increased ALP activity statistically $(P<0.05)$.

Conclusion: It can be concluded that AML had neither a positive nor a negative effect on bone healing, but when used in combination with PRP, it may be beneficial.

Keywords: amlodipine, calcium channel blockers, platelet-rich plasma, bone mineral metabolism, hypertension

\section{Introduction}

High blood pressure is estimated to affect more than one in three adults aged 25 and over, or about 1 billion people worldwide. ${ }^{1}$ This means that nearly $30 \%$ of our patients are suffering from hypertension. Various drugs are currently used to treat hypertension, but the effects of these drugs on other age-related problems have not been well studied. Drugs that are the primary choice for the treatment of hypertension include calcium channel blockers (CCBs). ${ }^{2}$ Dihydropyridine derived CCBs, such as amlodipine (AML), lacidipine, and nicardipine, are widely used to treat hypertension. Large clinical trials have confirmed their usefulness for preventing cardiovascular events by lowering blood pressure and having an antioxidant effect on vessels in vitro..$^{3,4}$

CCBs primarily inhibit calcium influx through the L-type voltage-dependent calcium channels at the level of vascular smooth muscle, thereby disrupting the excitationcontraction process. ${ }^{5,6}$ However, as these CCBs interfere in the transportation of calcium through cell membranes, they may affect many metabolic processes, including bone metabolism. ${ }^{7,8}$ A number of clinical and experimental studies have reported that the effects of CCBs are associated with skeletal calcium metabolism due to the presence of L-type calcium channels in osteoblastic cells. ${ }^{9}$ Regulators of bone formation modulate the channel's expression, suggesting a functional involvement of L-type calcium channels in bone remodeling. ${ }^{10} \mathrm{AML}$ is a third generation dihydropyridine L-type CCB used in the treatment of angina pectoris, arterial hypertension, and cardiac arrhythmias. ${ }^{11}$ 
Chronic use of CCBs in hypertensive patients may affect the repair process of osteogenesis after surgical and clinical procedures and may be important in the healing period, especially in guided bone regeneration procedures. There are disparate results in literature on the effects of CCBs on bone metabolism. Halici et al ${ }^{12}$ suggested that AML has a beneficial effect on bone metabolism and an antihypertensive effect. Moraes et a ${ }^{13}$ stated that chronic use of AML compromised bone formation in the early stage of the repair process of surgical defects in the ramus of rat mandible. Ushijima et al ${ }^{14}$ showed that AML prevents reduction in bone density during repeated dosing in stroke-prone, spontaneously hypertensive rats. However, Shimizu et al ${ }^{9}$ proposed that AML showed no action on bone metabolism in ovariectomized hypertensive rats. Despite the convincing evidence given above, there are insufficient data about the effects of CCB use on bone physiology in humans.

During wound healing, platelets are among the first cells to respond at a wound site, as they are critical to the initiation of this process. ${ }^{15-17}$ Recently, platelet rich plasma (PRP) has become a valuable adjunct used to promote healing in many procedures such as oral surgery, periodontology, otolaryngology, head-neck surgery, and neurosurgery. ${ }^{18,19}$ PRP is a product derived from autologous blood, and its preparation is intended to obtain a high platelet concentration in a small volume of plasma. One of the potential advantages of PRP is that it is possible for it to be obtained from the patient's own blood after a simple centrifugation procedure. ${ }^{20}$ Both, the plasma and its preparates contain growth factors that play a role during the initial phase of healing and bone regeneration. ${ }^{21,22}$

Various authors have described PRP as an effective means of improving the healing of both hard and soft tissues, resulting in reductions in pain, inflammation, and trismus, as well as an acceleration of the bone regeneration process. However, there are some controversial results in the literature, and there have been low numbers of systematic studies carried out to date. ${ }^{23,24}$

The rapid recovery after surgical procedures is crucial in order to regain normal functioning of the bone and its surrounding structures. There have been an increasing number of studies on this subject. ${ }^{25}$ The purpose of this study was to make a biochemical and histological evaluation of the effects of AML, PRP, and a combination of both materials on the repair process of a surgical defect in rat tibia, as well as to verify possible alterations in alkaline phosphatase (ALP) and serum bone-specific alkaline phosphatase (s-bone ALP) levels.

\section{Materials and methods Experimental design: animals and AML, PRP administration}

The study included 56 male Wistar Albino rats (mean age 12 weeks; weight $290-350 \mathrm{~g}$ ) and was conducted at the Health Institution of Research Centre, Afyon Kocatepe University, Afyonkarahisar, Turkey. The animals were housed in groups of seven per plastic cage in a controlled environment $\left(22^{\circ} \mathrm{C}\right.$; 12 -hour light-dark cycle) with free access to drinking water and a diet of standard laboratory rat food pellets. The experimental protocol of the study was approved by the Animal Experimentation Ethics Committee of Kocatepe University (2013-49533702/361). The animals were maintained and used in accordance with the animal welfare act and guidance for the care and use of laboratory animals. The rats were randomly divided into four groups:

- Group A (control group), tibia defect model with no treatment ( $\mathrm{n}=14)$;

- Group B (AML group), tibia defect model treated with AML, $0.04 \mathrm{mg} / \mathrm{rat} /$ day by oral gavage $(\mathrm{n}=14)$;

- Group C (PRP group), tibia defect model treated with local PRP ( $\mathrm{n}=14)$;

- Group D (AML + PRP group), tibia defect model treated with $0.2 \mathrm{~mL}$ local PRP and with AML $0.04 \mathrm{mg} / \mathrm{rat} / \mathrm{day}$ by oral gavage $(\mathrm{n}=14)$.

Groups A and $\mathrm{C}$ received daily oral doses of sterile physiological saline $(0.9 \% \mathrm{NaCl})$ in order to simulate any possible influence of physiological and physical stress on bone healing caused by gavage.

\section{Chemicals}

Amlodis (5 mg tablet) and cefamezin ( $1 \mathrm{~g}$ vial) were purchased from Zentiva (Istanbul, Turkey). Ketalar $10 \mathrm{~mL}$ was purchased from Pfizer (Istanbul, Turkey) and xylazine $25 \mathrm{~mL}$ was purchased from Bayer (Istanbul, Turkey). AML was dissolved in sterile physiological saline $(0.9 \% \mathrm{NaCl})$ and diluted to the given concentration.

\section{PRP preparation}

Blood was obtained from two rats after anesthesia; a total of $20 \mathrm{~mL}$ of whole blood from two rats was collected through intracardiac aspiration and mixed with $2 \mathrm{~mL}$ of the anticoagulant, citrate dextrose A. After centrifugation at 3,500 rpm for 12 minutes, red blood cells, PRP, and platelet-poor plasma were separated. The PRP was divided into $0.2 \mathrm{~mL}$ portions for each rat in these two groups. The total platelet count in $1 \mathrm{~mL}$ of prepared PRP was determined and confirmed with a phase-contrast microscopic platelet count. The concentration 
of the platelets in the two groups receiving PRPs was between $500,000-600,000 / \mu \mathrm{L}$.

\section{Rat tibia defect model and surgical procedure}

Surgical procedures were performed under general anesthesia with a combination of ketamine chlorhydrate (Ketalar; Pfizer $0.08 \mathrm{~mL} / 100 \mathrm{~g}$ body weight) and xylazine 2\% (Rompun; Bayer; $0.04 \mathrm{~mL} / 100 \mathrm{~g}$ body weight). A monocortical bone defect on the left tibia was created in all animals. Taking the right and left legs into a flexion position, the overlying skin of the left tibia was shaved and disinfected with iodated alcohol. A $1.5-\mathrm{cm}$ skin and muscle incision was then made to expose the bone surface of the middle third of the tibia where, on the wider region, a monocortical defect was created. A $1 \mathrm{~mm}$ diameter rod and a size 12 stainless steel dental burr (Meisinger GmbH, Neuss, Germany) were used on a lowspeed hand piece, under constant sterile saline irrigation, to create an oval bone defect measuring approximately $2 \mathrm{~mm}$ in width and $3 \mathrm{~mm}$ in length, with the cortical thickness. The muscular layer was sutured with resorbable 5.0 catgut suture (Dogsan, Trabzon, Turkey), and the skin was sutured with interrupted 3.0 silk suture (Dogsan). Upon completion of the surgical procedure, each animal received a single dose of cefazolin sodium, $50 \mathrm{mg} / \mathrm{kg}$ (Cefamezin; Zentiva) by intramuscular injection.

\section{Histopathological and biochemical evaluation}

Following surgery, seven rats per study group were killed on days 21 and 30, using high dose combination of ketamine and xylazine. Bone regeneration and fibrotic healing were evaluated by histopathology. Histological samples were fixed in $10 \%$ formalin for 72 hours and decalcified in $10 \%$ ethylenediamine tetraacetic acid (EDTA) solution (for decalcification) for approximately 2 months. After complete decalcification, dehydration was carried out in a graded alcohol series, and the samples were embedded in paraffin blocks. Transverse sections of 4-5 $\mu \mathrm{m}$ thickness were prepared for each tibia defect. All slices were stained with hematoxylin and eosin. Histological examination of the slides was carried out using a light microscope. All parameters were evaluated by an experienced pathologist, using a histological scoring technique. The pathologist was blinded to the study groups that each specimen came from. Healed bone was observed in the repair stage of healing in all the groups. Findings of fibrous tissue, cartilage tissue, immature ossification, and mature bone formation were seen in the groups. According to these findings, semiquantitative classification of the bone healing was made as follows:

- Good healing $=$ three $(3)$ points $=$ Trabecular bone with lamellar bone cells and compact bone (mature bone).

- Fair healing = two (2) points = Trabecular bone with wowen bone cells (immature bone).

- Poor healing $=$ one $(1)$ point. $=$ Fibrous and cartilage tissue.

Blood samples were collected at the time of sacrifice by cardiac puncture and centrifuged for plasma separation. For biochemical examination, serum samples were frozen at $-20^{\circ} \mathrm{C}$, until the measurement. ALP levels were measured using an autoanalyzer (Cobas C501; Roche Diagnostics, IN, USA) in the biochemistry laboratories of Afyon Kocatepe University. The results were expressed as units/liter.

\section{Statistical analyses}

The statistical calculations were carried out with the SPSS software package, version 15.0 (SPSS Inc., Chicago, IL, USA) for Windows. Results for descriptive statistics were expressed as mean \pm standard deviation (SD). Statistical comparisons of continuous and multiple variables among the groups were performed using Kruskal-Wallis test, based on their distribution. According to the Kruskal-Wallis test, statistical significance was observed, and the Mann-Whitney $U$-test was used to determine the difference between two groups. $P$-values less than 0.05 was considered as statistically significant.

\section{Results}

None of the rats in any group died during the course of the experiment. No unwanted condition developed in any rat, and none of the rats were excluded from the study. All of the animals tolerated the procedure well and demonstrated good homeostasis and rapid recovery from anesthesia.

\section{Histopathological results}

According to multiple comparisons with Kruskal-Wallis test, there were significant differences among all study groups at day $21(P<0.05)$, but no significant differences at day 30 $(P>0.05)$. Using pairwise comparisons with Mann-Whitney $U$-test, there was no statistically significant difference between days 21 and 30 in group $\mathrm{B}(P>0.05)$. The level of bone healing in groups $\mathrm{C}(\mathrm{PRP})$ and $\mathrm{D}(\mathrm{AML}+\mathrm{PRP})$ was significantly higher than that of group A (control) at day 21 $(P<0.05)$. There was also significantly better healing in group $\mathrm{D}(\mathrm{AML}+\mathrm{PRP})$ than group A (control) at day $30(P<0.05)$ (Table 1) (Figures 1-8). 
Table I Statistical analysis of bone healings at days 21 and 30

\begin{tabular}{|c|c|c|c|c|c|}
\hline & \multicolumn{4}{|c|}{ Study groups } & \multirow{2}{*}{$\begin{array}{l}P \text {-value } \\
\text { Kruskal-Walli } \\
\text { test }\end{array}$} \\
\hline & $\begin{array}{l}\text { Group A } \\
(n=14)\end{array}$ & $\begin{array}{l}\text { Group B } \\
(n=14)\end{array}$ & $\begin{array}{l}\text { Group C } \\
(n=14)\end{array}$ & $\begin{array}{l}\text { Group D } \\
(n=14)\end{array}$ & \\
\hline Day 21 & $1.57 \pm 0.53$ & $1.71 \pm 0.48$ & $2.57 \pm 0.53$ & $2.7 I \pm 0.48$ & $0.002^{*, d}$ \\
\hline Mann-Whitney U-test & & $0.591^{\mathrm{a}}$ & $0.0 I^{*, b}$ & $0.005^{*, c}$ & \\
\hline Day 30 & $2.00 \pm 0.81$ & $2.28 \pm 0.75$ & $2.7 I \pm 0.48$ & $2.85 \pm 0.37$ & $0.089^{e}$ \\
\hline Mann-Whitney U-test & & $0.493^{\mathrm{a}}$ & $0.08^{\mathrm{b}}$ & $\left.0.03\right|^{*, c}$ & \\
\hline Mann-Whitney U-test & & $0.116^{4}$ & $\left.0.59\right|^{g}$ & $0.530^{\mathrm{h}}$ & \\
\hline
\end{tabular}

Notes: *Statistically significant between-group difference $\left(P<0.05\right.$ Mann-Whitney $U$-test and Kruskal-Wallis test). Data are shown as mean \pm standard deviation. ${ }^{a} G$ roup $B$ compared with group A. 'broup C compared with group A. 'Group D compared with group A. 'Between-group comparisons at day 21 . e'Between-group comparisons at

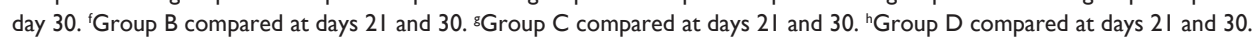

\section{ALP serum level results}

The serum levels of ALP and s-bone ALP showed statistically significant mean values for the experimental groups when compared with the control group. Changes in ALP levels as a bone remodeling marker after treatments are given in Tables 2 and 3. According to multiple comparisons with KruskalWallis test, there were significant differences among all the study groups at day $21(P<0.05)$, but no significant differences at day $30(P>0.05)$. Statistically (with Mann-Whitney $U$-test), AML did not affect ALP and s-bone ALP activity at 21 and 30 days $(P>0.05)$, but PRP and AML + PRP increased ALP and s-bone ALP activity statistically $(P<0.05)$.

\section{Discussion}

This study aimed at assessing the possible effects of antihypertensive drugs and PRP on bone healing. The effects of AML and PRP on the healing stage of a tibial bone defect in rats were evaluated by histopathological analyses, and levels of ALP were also examined.

Hypertension is one of the major challenges for public health. Appropriate hypertension treatment with antihypertensive drugs seems to provide a better quality of life

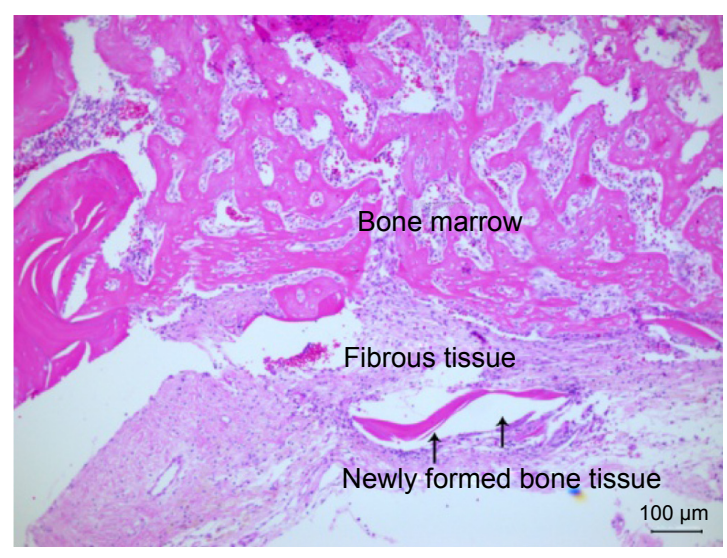

Figure I Control group at day 2I (hematoxylin and eosin, 100x). with low morbidity and mortality rates. CCBs, angiotensinconverting enzyme inhibitors, angiotensin II receptor type 1 antagonists, diuretics, $\beta$-blockers, and $\alpha$-blockers may be used as a primary choice for the treatment of hypertension. As CCBs are widely used in the treatment of hypertension and angina, ${ }^{12}$ AML was selected as the working material for this study. The daily dose used was $0.04 \mathrm{mg}$ of AML, consistent with the prescription for humans of 5-10 mg/day, the lower dose being suggested for elderly patients and those with hepatic insufficiency. ${ }^{24}$

The outcome of various clinical and surgical procedures in the treatment of bone defects is affected by several factors such as patient, defect, and surgical variables. An awareness of systemic conditions and drugs that could affect alveolar bone may be important to identify patients at increased risk of poor clinical and postoperative results. Thus, the present study focused on the impact of AML on defect healing. The physiological, cellular, and molecular mechanisms by which antihypertensive drugs may affect bone tissues are not yet fully understood, and to the best of our knowledge, there is limited information about the relationship between bone defect healing and AML.

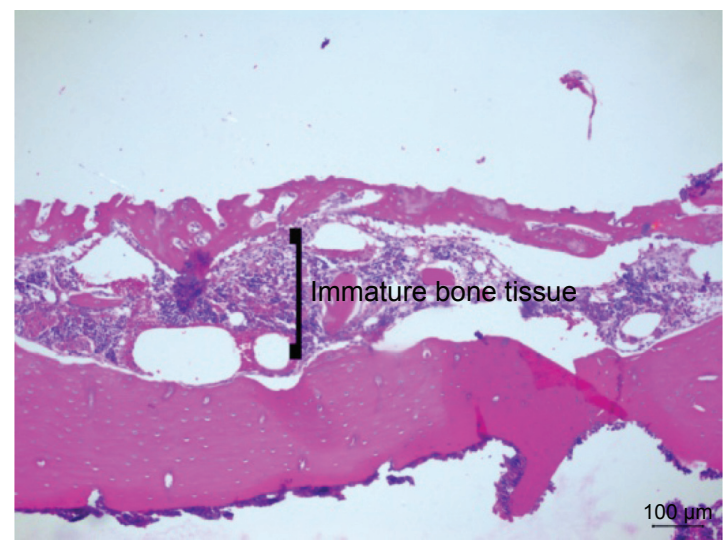

Figure 2 AML group at day 21 (hematoxylin and eosin, $100 \times$ ). Abbreviation: AML, amlodipine. 


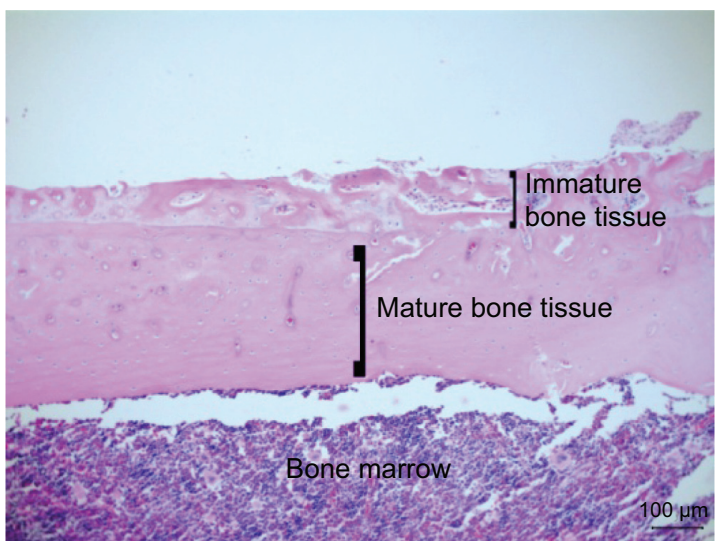

Figure 3 PRP group at day 21 (hematoxylin and eosin, 100x). Abbreviation: PRP, platelet rich plasma.

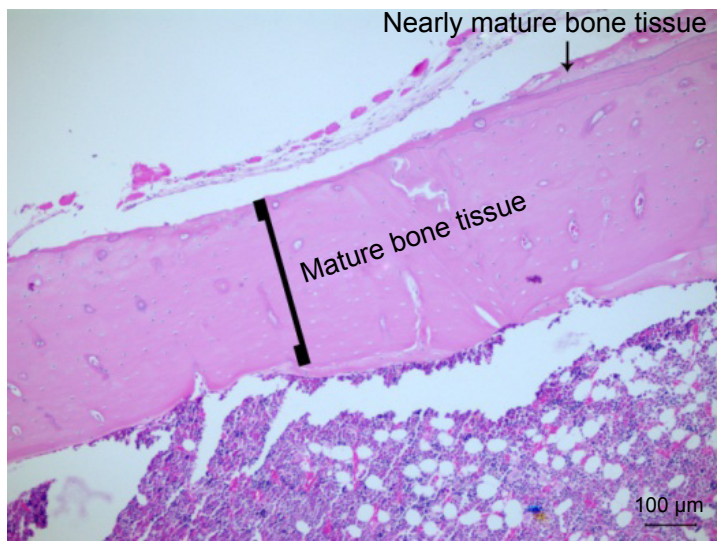

Figure $4 \mathrm{AML}+\mathrm{PRP}$ group at day $2 \mathrm{I}$ (hematoxylin and eosin, 100 $\times$ ). Abbreviations: AML, amlodipine; PRP, platelet rich plasma.

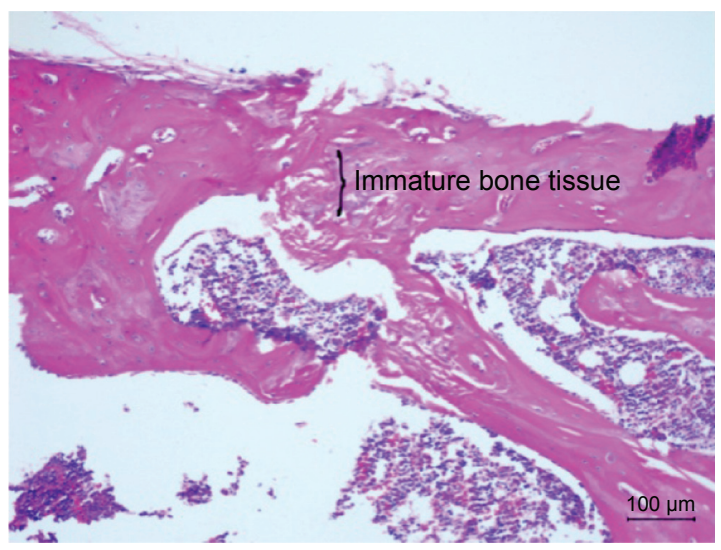

Figure 5 Control group at day 30 (hematoxylin and eosin, 100×).

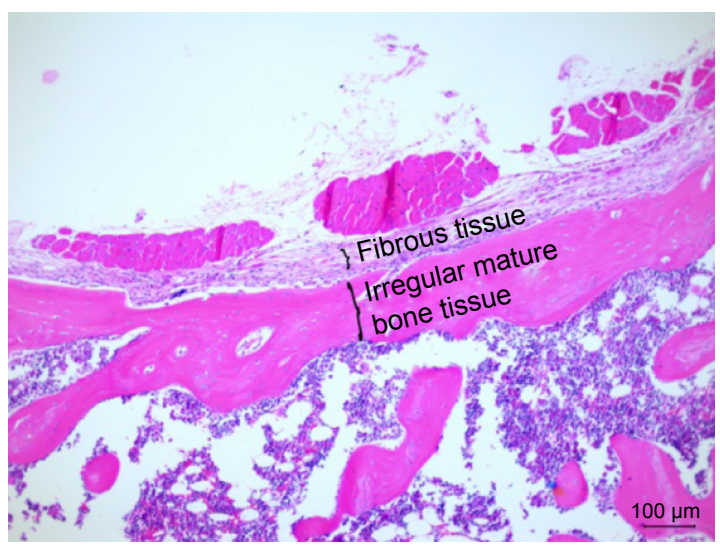

Figure 6 AML group at day 30 (hematoxylin and eosin, 100x). Abbreviation: AML, amlodipine.

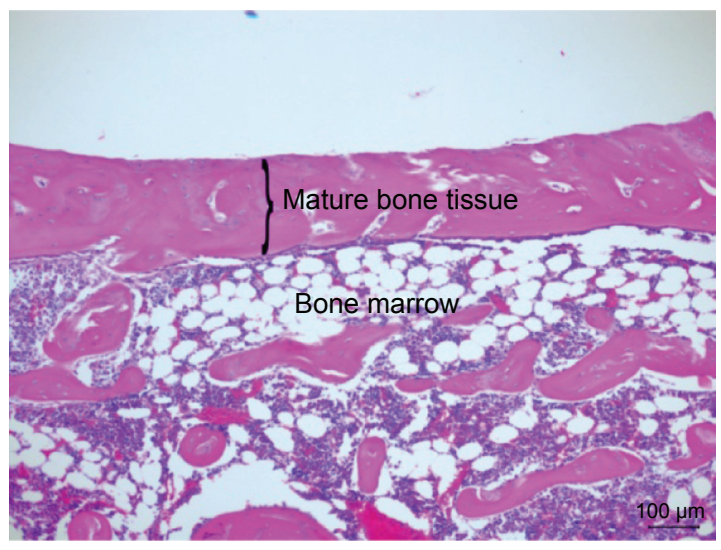

Figure 7 PRP group at day 30 (hematoxylin and eosin, 100×).

Abbreviation: PRP, platelet rich plasma.

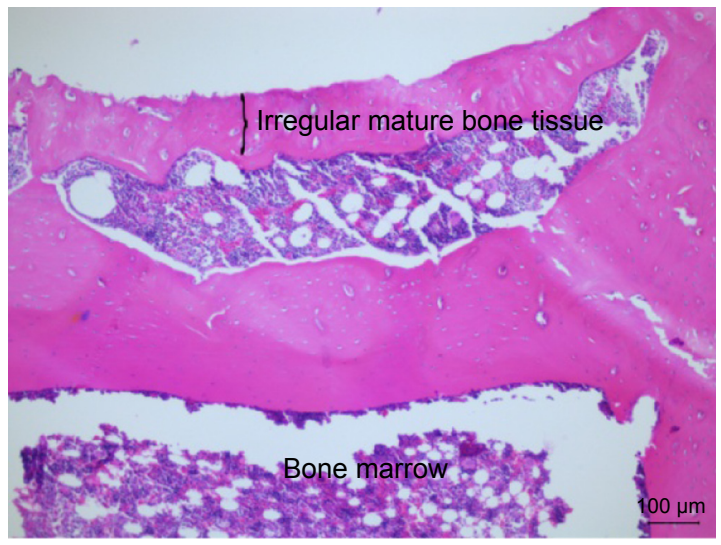

Figure 8 AML + PRP group at day 30 (hematoxylin and eosin, 100×). Abbreviation: AML, amlodipine, PRP, platelet rich plasma. 
Table 2 Statistical analysis of alkaline phosphatase levels at days 21 and 30

\begin{tabular}{|c|c|c|c|c|c|}
\hline & \multicolumn{4}{|l|}{ Study groups } & \multirow{2}{*}{$\begin{array}{l}\text {-value } \\
\text { Kruskal-Wallis } \\
\text { test }\end{array}$} \\
\hline & $\begin{array}{l}\text { Group A } \\
(n=14)\end{array}$ & $\begin{array}{l}\text { Group B } \\
(n=14)\end{array}$ & $\begin{array}{l}\text { Group C } \\
(n=14)\end{array}$ & $\begin{array}{l}\text { Group D } \\
(n=14)\end{array}$ & \\
\hline Day 21 & $94.28 \pm 17.90$ & $113.42 \pm 34.42$ & $128.00 \pm 20.67$ & $133.57 \pm 39.17$ & $0.069^{d}$ \\
\hline Mann-Whitney U-test & & $0.306^{\mathrm{a}}$ & $0.013^{*, b}$ & $0.035^{*, c}$ & \\
\hline Day 30 & $112.00 \pm 10.67$ & $126.00 \pm 19.17$ & $145.28 \pm 27.03$ & $|84.28 \pm| 4.25$ & $0.00 I^{*, e}$ \\
\hline Mann-Whitney U-test & & $0.224^{\mathrm{a}}$ & $0.029 * b$ & $0.002^{*, c}$ & \\
\hline Mann-Whitney U-test & & $0.249^{f}$ & $0.224^{\mathrm{g}}$ & $0.015^{*, h}$ & \\
\hline
\end{tabular}

Notes: *Statistically significant between-group difference $\left(P<0.05\right.$ Mann-Whitney $U$-test and Kruskal-Wallis test). Data are shown as mean \pm standard deviation. ${ }^{a} G$ roup $B$ compared with group A. 'broup C compared with group A. 'Group D compared with group A. 'Between-group comparisons at day 21 . e'Between-group comparisons at day 30. 'Group B compared at days 21 and 30. ${ }^{g}$ Group $C$ compared at days 21 and 30 . 'h Group D compared at days 21 and 30.

The results of the current study showed that AML had neither a positive nor a negative effect on bone defect healing, although the combination of AML and PRP could be beneficial to the defect healing process. To the best of the authors' knowledge, this is the first study that used an AML and PRP combination for the treatment of a bone defect. These results may have arisen due to the synergistic effect of AML and PRP on bone healing. A study by Teófilo et al, ${ }^{8}$ demonstrated the alveolar bone repair process in rats under conditions of chronic AML, used at a dose identical to that of the current study; a decrease from $20 \%$ to $30 \%$ in the volume of newly formed bone was reported. In another study by Moraes et $\mathrm{al}^{13}$ a period of 14 and 30 days was evaluated for both the AML and control groups, and newly formed bone was reduced when compared with the control group in 14 days, but AML did not affect newly formed bone in 30 days, with the same dose as used as in the current study. Gradošová et $\mathrm{al}^{26}$ assumed that AML did not significantly influence bone mineral density for 8 weeks. However, 1 year before this study, Gradošová et al ${ }^{27}$ suggested that AML could prevent osteoporosis for 12 weeks. A study by Ushijima et $\mathrm{al}^{14}$ reported that AML prevented the reduction of bone density of the femur. Accordingly, amlodipine and lacidipine prevented ovariectomy-induced bone loss in osteopenic rat femur. ${ }^{12}$ Despite the numerous studies mentioned above, there is insufficient knowledge about the effects of CCB use on bone healing metabolism.

During the last 20 years, PRP has been used to enhance bone regeneration and soft tissue maturation for maxillofacial surgery as well as periodontology, ranging from filling postextraction alveolar sockets to more complex surgery. ${ }^{28-31}$ PRP can be used alone or in conjunction with bone grafts in the surgical site. ${ }^{24}$ It is prepared with the intention of influencing soft and hard tissue repair and/or regeneration. ${ }^{32}$ It is thought that the contribution of PRP to the bone healing process is based on the growth factors present in it which promote proliferation, chemotaxis, and the differentiation of cells which are essential to osteogenesis. The concentration of growth factors is seven times higher in PRP than in normal blood clots. ${ }^{33}$ PRP contains growth factors such as platelet-derived growth factor, epithelial growth factor, transforming growth factor- $\beta$, vascular endothelial growth factor, insulin growth factor-1, and basic fibroblast growth factor. ${ }^{24,34}$ Therefore, PRP may influence bone healing through a variety of pathways. In addition, PRP has been reported to have benefits such as the improved handling of particulate grafts, facilitation of graft placement and stability, improved rate and quality of new bone formed, hemostasis when used in conjunction with the cell-poor serum layer containing factor Xa, shorter implant exposure time, enhanced vascular

Table 3 Statistical analysis of serum bone-specific alkaline phosphatase at days 21 and 30

\begin{tabular}{|c|c|c|c|c|c|}
\hline & \multicolumn{4}{|c|}{ Study groups } & \multirow{2}{*}{$\begin{array}{l}\text { P-value } \\
\text { Kruskal-Walli } \\
\text { test }\end{array}$} \\
\hline & $\begin{array}{l}\text { Group A } \\
(n=14)\end{array}$ & $\begin{array}{l}\text { Group B } \\
(n=14)\end{array}$ & $\begin{array}{l}\text { Group C } \\
(n=14)\end{array}$ & $\begin{array}{l}\text { Group D } \\
(n=14)\end{array}$ & \\
\hline Day 21 & $77.57 \pm|8.4|$ & $81.85 \pm 24.79$ & $101.57 \pm 14.10$ & $101.42 \pm 26.47$ & $0.072^{\mathrm{d}}$ \\
\hline Mann-Whitney U-test & & $0.565^{a}$ & $0.02 I^{*, b}$ & $0.048^{*, c}$ & \\
\hline Day 30 & $89.28 \pm 10.90$ & $97.7 \mid \pm 18.58$ & $116.28 \pm 24.17$ & $151.57 \pm 8.69$ & $0.00 I^{*, e}$ \\
\hline Mann-Whitney U-test & & $0.443^{\mathrm{a}}$ & $0.025^{*, \mathrm{~b}}$ & $0.002^{*, c}$ & \\
\hline Mann-Whitney U-test & & $0.18^{f}$ & $0.276^{g}$ & $0.003^{*, \mathrm{~h}}$ & \\
\hline
\end{tabular}

Notes: *Statistically significant between-group difference $\left(P<0.05\right.$ Mann-Whitney U-test and Kruskal-Wallis test). Data are shown as mean \pm standard deviation. a ${ }^{2}$ roup $B$ compared with group A. 'broup C compared with group A. 'Group D compared with group A. 'Between-group comparisons at day 21 . eBetween-group comparisons at day 30. ${ }^{\mathrm{f}}$ Group B compared at days 21 and 30. ${ }^{8}$ Group C compared at days 21 and 30. ${ }^{\mathrm{h}}$ Group D compared at days 21 and 30. 
ingrowth, mitogenic effects, natural biological sealant, no risk of disease transmission due to its autologous nature, and it is not expensive. ${ }^{35}$

The vast majority of published clinical studies suggests that PRP accelerated bone healing, ${ }^{18,23,36-41}$ while other authors have reported different results. ${ }^{42-48}$ The scientific evidence regarding the efficacy and efficiency of PRP is still controversial. However, in a recent study, Daif ${ }^{49}$ investigated the effect of autologous PRP on bone regeneration in mandibular fractures. The authors concluded that direct application of PRP along the fracture lines may enhance bone regeneration. Similarly, PRP improved bone repair alone, not in 30 days, but in 21 days. PRP alone has a strong stimulant effect on capillary regeneration in wound healing. These effects are mainly noticeable during the early stages of wound healing. ${ }^{50}$

Controversial results regarding the effectiveness of PRP may partly be due to wide variations in manufacturing methods. ${ }^{51}$ It has been reported that differences in proportion and levels of growth factors may be found between currently available commercial PRP systems because of the concentration of platelet that, in turn, may affect results. ${ }^{52}$ Differences in the results of the studies might also be related to the study design.

ALP activities may serve as markers of the course and rate of bone healing. ALP activity is a marker for the differentiation of cells with osteogenic potential into mature osteoblasts. ${ }^{53}$ ALP is generally considered to play a key role in calcification in vitro. Calcification does not occur in the absence of ALP activity. ${ }^{54}$ ALP was evaluated as a boneremodeling marker by biochemical analysis in the current study. In this study, there was no statistically significant difference in the serum levels of ALP and s-bone ALP between the control group and the AML groups for the periods after 21 and 30 days. Similar to the histopathological results, the combination of AML and PRP increased the ALP levels. There are controversial results in literature about the metabolism of ALP. Teófilo et $\mathrm{al}^{8}$ demonstrated that ALP levels of the AML groups were of nearly the same concentration as in the control group at day 30 , but there was a significant decrease at day 14 . Gradošová et $\mathrm{al}^{26}$ suggested that the serum concentration of s-bone ALP greatly decreased to $12 \%$ in the AML group in comparison with the control group. On the other hand, Kosaka and Uchii ${ }^{55}$ found that benidipine, a CCB, increased ALP activity of osteoblastic cells isolated from neonatal mouse calvaria.

The findings of the current study revealed the positive effects of PRP on ALP activities. There are contradicting results in the literature about this issue. Arpornmaeklong et $\mathrm{al}^{56}$ reported that PRP reduced ALP activity. Kasten et $\mathrm{al}^{57}$ showed that addition of PRP reduced the ALP activity in mesenchymal stem cells in $\beta$-tricalcium phosphate (MSC/ beta-TCP) composites significantly at explantation. In accordance with our study and incompatible with the above mentioned studies, Chen et $\mathrm{al}^{58}$ showed significantly increased ALP concentration in blood at 4 weeks in the PRP group. The mechanisms of effects of CCBs and PRP have not been fully understood yet, but they are mostly attributed to changes in bone remodeling. These effects might be based on the relationship between osteoblastic and osteoclastic activity. However, the variability in the histopathological and biochemical results of the studies can be related to the differences in methodological designs.

There are also some limitations of the present study. A single dose of AML ( $0.04 \mathrm{mg} / \mathrm{rat} /$ day $)$ was applied to the rats, and it can be speculated about the effect of different dosing regimens on bone defect healing. However, there are some ethical restrictions due to the increase in the number of animals for different dosing regimens. Another limitation was that in the current study, the immunohistochemical expression of the markers, osteopontin, osteonectin, and osteocalcin, that play an important role in the mineralization and healing of the bone could not be examined. Besides, histopathologic and serum findings could not be supported with radiographic measures to determine the healing outcome of the study groups. The current study has other limitations, such as the brief monitoring period as well as the fact that there was no hemodynamic monitoring of the animals during our experiment.

\section{Conclusion}

It can be concluded that AML had neither a positive nor a negative effect on bone healing at the repair stage. However if AML is used in combination with PRP, it could be beneficial. PRP is beneficial in the tibial healing process both at 21 days. In light of these results, PRP, especially, could be a viable alternative to accelerate the healing of bone in the early stages. The results of the present study can provide valuable contributions to the literature. But in the daily clinical practice, many clinicians are still skeptical about the current levels of evidence about the impact of CCBs on bone mineral metabolism and efficacy of PRP on soft/hard tissue healing. High quality, robust, randomized controlled studies are needed to investigate the effects of different dose regimens of AML and PRP in the promotion of bone healing. Such information from in vivo/in vitro studies may clarify 
the potent action of AML and PRP on bone defect healing and may lead to finding a novel therapeutic target for surgical procedures, and systemic and bone diseases.

\section{Acknowledgment}

This study was supported by the Scientific Research Projects of Afyon Kocatepe University (Project no: 13.DIS.01).

\section{Disclosure}

The authors report no conflicts of interest in this work.

\section{References}

1. World Health Organization. World Health Day 2013: Measure Your Blood Pressure, Reduce Your Risk. Geneva, Switzerland: World Health Organization. Available from: http://www.who.int/mediacentre/news/ releases/2013/world_health_day_20130403/en/. Accessed February 19, 2015.

2. World Health Organization, International Society of Hypertension. 1999 World Health Organization-International Society of Hypertension Guidelines for the Management of Hypertension. Guidelines Subcommittee. J Hypertens. 1999;17:151-183.

3. Civantos B, Aleixandre A. Blood pressure and $\alpha$-vascular reactivity in hypertensive rats treated with amlodipine and dietary Ca. Eur J Pharmacol. 2004;489:101-110.

4. Rosenkranz AC, Lob H, Breitenbach T, Berkels R, Roesen R. Endothelial antioxidant actions of dihydropyridines and angiotensin converting enzyme inhibitors. Eur J Pharmacol. 2006;529:55-62.

5. Opie LH. Calcium Antagonists and Cardiovascular Disease. New York, NY: Raven Press; 1984.

6. Katz AM, Hager WD, Messineo FC, Pappano AJ. Cellular actions and pharmacology of the calcium channel blocking drugs. Am J Med. 1984; 77:2-10.

7. Duriez J, Flautre B, Blary M, Duriez R. Effet d'un inhibiteur calcique, le vérapamil, sur le développement des ossifications hétérotopiques. [Effect of a calcium inhibitor, verapamil, on the development of heterotopic ossifications. An experimental study in rats]. Int Orthop. 1989; 14(4):415-421. French.

8. Teófilo J, Brentegani L, Lamano Carvalho T. A histometric study in rats of the effect of the calcium antagonist amlodipine on bone healing after tooth extraction. Arch Oral Biol. 2001;46:375-379.

9. Shimizu H, Nakagami H, Yasumasa N, et al. Cilnidipine, but not amlodipine, ameliorates osteoporosis in ovariectomized hypertensive rats through inhibition of the N-type calcium channel. Hypertens Res. 2011;35:77-81.

10. Gu Y, Preston M, Magnay J, El Haj A, Publicover S. Hormonallyregulated expression of voltage-operated $\mathrm{Ca}(2+)$ channels in osteocytic (MLO-Y4) cells. Biochem Biophys Res Commun. 2001;282: 536-542.

11. Hedner T. Calcium channel blockers: spectrum of side effects and drug interactions. Acta Pharmacol Toxicol. 1986;58:119-130.

12. Halici Z, Borekci B, Ozdemir Y, Cadirci E, Suleyman H. Protective effects of amlodipine and lacidipine on ovariectomy-induced bone loss in rats. Eur J Pharmacol. 2008;579:241-245.

13. Moraes RB, Corrêa L, Luz JG. Adverse effects of the amlodipine on bone healing of the mandibular fracture: an experimental study in rats. Oral Maxillofac Surg. 2011;15:93-101.

14. Ushijima K, Liu Y, Maekawa T, et al. Protective effect of amlodipine against osteoporosis in stroke-prone spontaneously hypertensive rats. Eur J Pharmacol. 2010;635:227-230.

15. El-Sharkawy H, Kantarci A, Deady J, et al. Platelet-rich plasma: growth factors and pro-and anti-inflammatory properties. J Periodontol. 2007;78:661-669.
16. Alsousou J, Thompson M, Hulley P, Noble A, Willett K. The biology of platelet-rich plasma and its application in trauma and orthopaedic surgery: a review of the literature. J Bone Joint Surg Br. 2009;91:987-996.

17. Anitua E, Andia I, Ardanza B, Nurden P, Nurden AT. Autologous platelets as a source of proteins for healing and tissue regeneration. Thromb Haemost. 2004;91:4-15.

18. Albanese A, Licata ME, Polizzi B, Campisi G. Platelet-rich plasma (PRP) in dental and oral surgery: from the wound healing to bone regeneration. Immunity Ageing. 2013;10:23.

19. Whitman DH, Berry RL, Green DM. Platelet gel: an autologous alternative to fibrin glue with applications in oral and maxillofacial surgery. J Oral Maxillofac Surg. 1997;55:1294-1299.

20. Guzel Y, Karalezli N, Bilge O, et al. The biomechanical and histological effects of platelet-rich plasma on fracture healing. Knee Surg Sports Traumatol Arthrosc. 2013:1-6.

21. Hall MP, Band PA, Meislin RJ, Jazrawi LM, Cardone DA. Platelet-rich plasma: current concepts and application in sports medicine. $J$ Am Acad Orthop Surg. 2009;17:602-608.

22. Lubowitz JH, Poehling GG. Shoulder, hip, knee, and PRP. Arthroscopy. 2010;26:141-142.

23. Del Fabbro M, Bortolin M, Taschieri S. Is autologous platelet concentrate beneficial for post-extraction socket healing? A systematic review. Int J Oral Maxillofac Surg. 2011;40:891-900.

24. Sánchez AR, Sheridan PJ, Kupp LI. Is platelet-rich plasma the perfect enhancement factor? A current review. Int J Oral Maxillofac Implants. 2002;18:93-103.

25. Anitua E, Sanchez M, Orive G, Andía I. The potential impact of the preparation rich in growth factors (PRGF) in different medical fields. Biomaterials. 2007;28:4551-4560.

26. Gradošová I, Živná H, Švejkovská K, Palička V, Tichý A, Živný P. Effects of amlodipine on bone metabolism in male albino Wistar rats. Acta Vet Brno. 2012;80:391-396.

27. Gradosova I, Zivna H, Palicka V, Hubena S, Svejkovska K, Zivny P. Protective effect of amlodipine on rat bone tissue after orchidectomy. Pharmacology. 2011;89:37-43.

28. Ersen A, Demirhan M, Atalar A, Kapicioğlu M, Baysal G. Plateletrich plasma for enhancing surgical rotator cuff repair: evaluation and comparison of two application methods in a rat model. Arch Orthop Trauma Surg. 2014;134:405-411.

29. Kutkut A, Andreana S, Kim H-L, Monaco E Jr. Extraction socket preservation graft before implant placement with calcium sulfate hemihydrate and platelet-rich plasma: a clinical and histomorphometric study in humans. J Periodontol. 2012;83:401-409.

30. Brugnami F, Corsi A, Riminucci M, Caiazzo A. A case report of bilateral mandibular vertical guided bone regeneration with and without bovine thrombin/calcium chloride activated platelet-rich plasma. J Oral Implantol. 2011;37:73-79.

31. Anitua E, Prado R, Orive G. Bilateral sinus elevation evaluating plasma rich in growth factors technology: a report of five cases. Clin Implant Dent Relat Res. 2012;14:51-60.

32. Anitua E. Plasma rich in growth factors: preliminary results of use in the preparation of future sites for implants. Int J Oral Maxillofac Implants. 1999;14:529-535.

33. Eskan MA, Greenwell H. Theoretical and clinical considerations for autologous blood preparations: platelet-rich plasma, fibrin sealants, and plasma-rich growth factors. Clin Adv Periodontics. 2011;1:142-153.

34. Tözüm TF, Demiralp B. Platelet-rich plasma: a promising innovation in dentistry. J Can Dent Assoc. 2003;69:664.

35. Boyapati L, Wang H-L. The role of platelet-rich plasma in sinus augmentation: a critical review. Implant Dent. 2006;15:160-170.

36. Camargo PM, Lekovic V, Weinlaender M, Vasilic N, Madzarevic M, Kenney EB. Platelet-rich plasma and bovine porous bone mineral combined with guided tissue regeneration in the treatment of intrabony defects in humans. J Periodontal Res. 2002;37:300-306.

37. Dallari D, Savarino L, Stagni C, et al. Enhanced tibial osteotomy healing with use of bone grafts supplemented with platelet gel or platelet gel and bone marrow stromal cells. J Bone Joint Surg. 2007;89:2413-2420. 
38. Garg A. The use of platelet-rich plasma to enhance the success of bone grafts around dental implants. Dental Implantol Update. 2000;11: 17-21.

39. Kitoh H, Kitakoji T, Tsuchiya H, et al. Transplantation of marrowderived mesenchymal stem cells and platelet-rich plasma during distraction osteogenesis - a preliminary result of three cases. Bone. 2004;35:892-898.

40. Marx RE, Carlson ER, Eichstaedt RM, Schimmele SR, Strauss JE, Georgeff KR. Platelet-rich plasma: growth factor enhancement for bone grafts. Oral Surg Oral Med Oral Pathol Oral Radiol Endod. 1998; 85:638-646.

41. Dianwen S, Gao H, Huazi X, et al. Platelet-rich plasma promotes healing of osteoporotic fractures. Orthopedics. 2013;36:e687-e694.

42. De Vasconcelos Gurgel BC, Gonçalves PF, Pimentel SP, et al. Plateletrich plasma may not provide any additional effect when associated with guided bone regeneration around dental implants in dogs. Clin Oral Implants Res. 2007;18:649-654.

43. Froum SJ, Wallace SS, Tarnow DP, Cho S-C. Effect of platelet-rich plasma on bone growth and osseointegration in human maxillary sinus grafts: three bilateral case reports. Int J Periodontics Restorative Dent. 2002;22:45-54.

44. Jensen TB, Rahbek O, Overgaard S, Søballe K. Platelet rich plasma and fresh frozen bone allograft as enhancement of implant fixation. An experimental study in dogs. J Orthop Res. 2004;22:653-658.

45. Calori G, Tagliabue L, Gala L, d'Imporzano M, Peretti G, Albisetti W. Application of rhBMP-7 and platelet-rich plasma in the treatment of long bone non-unions: a prospective randomised clinical study on 120 patients. Injury. 2008;39:1391-1402.

46. Pryor ME, Polimeni G, Koo KT, et al. Analysis of rat calvaria defects implanted with a platelet-rich plasma preparation: histologic and histometric observations. J Clin Periodontol. 2005;32:966-972.

47. Piemontese M, Aspriello SD, Rubini C, Ferrante L, Procaccini M. Treatment of periodontal intrabony defects with demineralized freeze-dried bone allograft in combination with platelet-rich plasma: a comparative clinical trial. J Periodontol. 2008;79:802-810.

48. Griffin X, Smith C, Costa M. The clinical use of platelet-rich plasma in the promotion of bone healing: a systematic review. Injury. 2009;40: $158-162$.
49. Daif ET. Effect of autologous platelet-rich plasma on bone regeneration in mandibular fractures. Dent Traumatol. 2013;29:399-403.

50. Lindeboom JA, Mathura KR, Aartman IH, Kroon FH, Milstein DM, Ince C. Influence of the application of platelet-enriched plasma in oral mucosal wound healing. Clin Oral Implants Res. 2007;18:133-139.

51. Anitua E, Sánchez M, Nurden AT, Nurden P, Orive G, Andía I. New insights into and novel applications for platelet-rich fibrin therapies. Trends Biotechnol. 2006;24:227-234.

52. Weibrich G, Kleis W, Hafner G. Growth factor levels in the plateletrich plasma produced by 2 different methods: curasan-type PRP kit versus PCCS PRP system. Int J Oral Maxillofac Implants. 2001;17: 184-190.

53. Wang H, Boerman OC, Sariibrahimoglu K, Li Y, Jansen JA, Leeuwenburgh SC. Comparison of micro-vs nanostructured colloidal gelatin gels for sustained delivery of osteogenic proteins: bone morphogenetic protein-2 and alkaline phosphatase. Biomaterials. 2012;33: 8695-8703.

54. Kisiel AH, McDuffee LA, Masaoud E, Bailey TR, Gonzalez BPE, Nino-Fong R. Isolation, characterization, and in vitro proliferation of canine mesenchymal stem cells derived from bone marrow, adipose tissue, muscle, and periosteum. Am J Vet Res. 2012;73:1305-1317.

55. Kosaka N, Uchii M. Effect of benidipine hydrochloride, a dihydropyridinetype calcium antagonist, on the function of mouse osteoblastic cells. Calcif Tissue Int. 1998;62:554-556.

56. Arpornmaeklong P, Kochel M, Depprich R, Kübler N, Würzler K. Influence of platelet-rich plasma (PRP) on osteogenic differentiation of rat bone marrow stromal cells. An in vitro study. Int J Oral Maxillofac Surg. 2004;33:60-70

57. Kasten P, Luginbühl R, Van Griensven M, et al. Comparison of human bone marrow stromal cells seeded on calcium-deficient hydroxyapatite, $\beta$-tricalcium phosphate and demineralized bone matrix. Biomaterials. 2003;24:2593-2603.

58. Chen T-L, Lu H-J, Liu G-Q, et al. Effect of autologous platelet-rich plasma in combination with bovine porous bone mineral and bio-guide membrane on bone regeneration in mandible bicortical bony defects. J Craniofac Surg. 2014;25:215-223.
Drug Design, Development and Therapy

\section{Publish your work in this journal}

Drug Design, Development and Therapy is an international, peerreviewed open-access journal that spans the spectrum of drug design and development through to clinical applications. Clinical outcomes, patient safety, and programs for the development and effective, safe, and sustained use of medicines are a feature of the journal, which

\section{Dovepress}

has also been accepted for indexing on PubMed Central. The manuscript management system is completely online and includes a very quick and fair peer-review system, which is all easy to use. Visit http://www.dovepress.com/testimonials.php to read real quotes from published authors. 